\title{
HUBUNGAN PENGETAHUAN, SIKAP, UMUR, PENDIDIKAN, PEKERJAAN, PSIKOLOGIS, DAN INISIASI MENYUSUI DINI DENGAN PEMBERIAN ASI EKSKLUSIF DI PUSKESMAS SUDIANG
}

\author{
RELATIONS OF KNOWLEDGE, ATTITUDE, AGE, EDUCATION, \\ JOBS, PSYCHOLOGICAL, AND EARLY ASKING INITIATIONS WITH \\ EXCLUSIVE ASSESSMENT IN SUDIANG PUSKESMAS
}

\author{
Hasna Assriyah ${ }^{1}$, Rahayu Indriasari ${ }^{1}$, Healthy Hidayanti ${ }^{1}$, Abdul Razak Thaha ${ }^{1}$, \\ Nurhaedar Jafar ${ }^{1}$ \\ (E-mail/Hp: hasna.assriyah1004@gmail.com/085314813248)
}

${ }^{1}$ Program Studi Ilmu Gizi, Fakultas Kesehatan Masyarakat, Universitas Hasanuddin, Makassar

\begin{abstract}
ABSTRAK
Pendahuluan Pemberian ASI secara dini dan eksklusif akan membantu mencegah berbagai penyakit anak, terutama gangguan lambung, saluran nafas dan asma pada anak. Faktor - faktor yang dapat mempengaruhi pemberian ASI eksklusif antara lain karakteristik ibu (pengetahuan, pendidikan, pekerjaan, usia, paritas dan etnis), karakteristik bayi (berat lahir dan kondisi kesehatan bayi), lingkungan (keyakinan, dukungan keluarga, tempat tinggal dan sosial ekonomi) dan pelayanan kesehatan (pemeriksaan kehamilan, konseling laktasi, tempat persalinan, penolong persalinan dan kebijakan). Tujuan: Penelitian ini adalah untuk mengetahui hubungan faktor ibu dan inisiasi menyusu dini (IMD) dengan pemberian ASI eksklusif. Bahan dan Metode: Jenis penelitian ini adalah analitik cross sectionalstudy. Penelitian ini dilakukan pada 95 ibu yang memiliki bayi usia 6-11 bulan di Wilayah Kerja Puskesmas Sudiang Makassar. Analisis dilakukan dengan uji chi-square untuk menentukan hubungan antar variable. Hasil: Hasil penelitian ini menunjukkan bahwa terdapat 50,5\% bayi tidak mendapatkan ASI eksklusif dan $49,5 \%$ bayi mendapatkan ASI eksklusif. Terdapat hubungan antara pengetahuan ibu $(\mathrm{p}=$ $0,015)$, pekerjaan ibu ( $\mathrm{p}=0,049)$, psikologis $(\mathrm{p}=0,031)$, dan inisiasi menyusui dini (IMD) ( $\mathrm{p}$ $=0,007)$ dengan pemberian ASI eksklusif. Tidak terdapat hubungan antara sikap ibu $(\mathrm{p}=$ $0,748)$, umur ibu $(\mathrm{p}=0,325)$, dan pendidikan ibu $(\mathrm{p}=0,558)$ dengan pemberian ASI eksklusif. Kesimpulan: Terdapat hubungan antara faktor ibu yaitu pengetahuan ibu, pekerjaan ibu, psikologis ibu dan inisiasi menyusu dini (IMD) dengan pemberian ASI eksklusif dan tidak terdapat hubungan faktor ibu yaitu sikap ibu, umur ibu dan pendidikan ibu dengan pemberian ASI eksklusif di Wilayah Kerja Puskesmas Sudiang Makassar.
\end{abstract}

Kata kunci : Pengetahuan, Sikap, Umur, Pendidikan, Pekerjaan, Psikologis, Inisiasi Menyusu Dini, ASI Eksklusif.

\begin{abstract}
Introduction: Breastfeeding exclusively and exclusively will help prevent various childhood illnesses, especially stomach disorders, respiratory tract and asthma in children. Factors that can influence exclusive breastfeeding include mother characteristics (knowledge, education, occupation, age, parity and ethnicity), baby characteristics (birth weight and infant health conditions), environment (beliefs, family support, place of residence and socioeconomic ) and health services (antenatal care, lactation counseling, place of delivery, birth attendants and
\end{abstract}


policies). Objective: this research was to determine the relationship between maternal factors and the initiation of early breastfeeding (IMD) with exclusive breastfeeding. Materials and Methods: This type of research is analytic cross sectional study. The study was conducted on 95 mothers who have babies aged 6-11 months in the Sudiang Makassar Public Health Center. Analysis was performed with the chi-square test to determine the relationship between variables. Results: The results of this study showed that 50.5\% of infants did not get exclusive breastfeeding and $49.5 \%$ of infants received exclusive breastfeeding. There is a relationship between mother's knowledge and exclusive breastfeeding $(p=0.015)$. There is a relationship between mother's work and exclusive breastfeeding $(p=0.049)$. There is a relationship between psychological and exclusive breastfeeding $(p=0.031)$. There was a relationship between the initiation of early breastfeeding $(I M D)$ and exclusive breastfeeding $(p=0.007)$. There was no relationship between maternal attitudes and exclusive breastfeeding $(p=0.748)$. There was no relationship between maternal age and exclusive breastfeeding $(p=0.325)$. There was no relationship between maternal education with exclusive breastfeeding $(p=0.558)$. Conclusion: There is a relationship between maternal factors namely mother's knowledge, mother's occupation, maternal psychology and initiation of early breastfeeding (IMD) with exclusive breastfeeding and there is no relationship between maternal factors namely mother's attitude, mother's age and mother's education with exclusive breastfeeding in the Puskesmas Work Area Sudiang Makassar.

Keywords: Knowledge, Attitude, Age, Education, Employment, Psychological, Early Breastfeeding Initiation (IMD), Exclusive breastfeeding.

\section{PENDAHULUAN}

Dalam rangka percepatan perbaikan gizi pemerintah telah mengeluarkan Peraturan Presiden nomor 42 tahun 2013 tentang Gerakan Nasional Percepatan Perbaikan Gizi yang fokus pada 1000 Hari Pertama Kehidupan (HPK). Sasaran global tahun 2025 disepakati adalah menurunkan proporsi anak balita yang pendek (stunting) sebesar $40 \%$, menurunkan proporsi anak balilta yang menderita kurus (wasting) < 5\%, menurunkan anak yang lahir berat badan rendah (BBLR) sebesar 30\%, tidak ada kenaikan proporsi anak yang mengalami gizi lebih, menurunkan proporsi ibu usia subur yang menderita anemia sebanyak 50\%, meningkatkan prosentase ibu yang memberikan ASI ekslusif selama 6 bulan lebih kurang 50\%. ${ }^{1}$

Berdasarkan Riskesdas tahun 2018, proporsi pola pemberian ASI eksklusif pada anak 0 -5 bulan tahun 2018 sebesar 37,3\% dan proporsi pemberian IMD sebesar 58,2\%. Sedangkan proporsi pemberian ASI eksklusif pada 0 - 6 bulan pada tahun 2013 sebesar 30,2\% dan proporsi IMD sebesar $34,5 \% .^{2}$ Hal ini menunjukan terjadinya peningkatan proporsi pemberian ASI eksklusif dan pemberian IMD. ${ }^{2}$ Sedangkan proporsi pemberian ASI eksklusif untuk Sulawesi Selatan tahun 2018 sebesar 35 - 40\%, sedangkan untuk proporsi IMD tahun 2018 sebesar 40 $60 \%{ }^{2}$

Penyebab kegagalan praktek ASI eksklusif bermacam-macam seperti pemberian makanan prelakteal, ibu harus bekerja, bayi sakit, ibu lelah/sakit, ibu kurang percaya diri, dan lainlain. ${ }^{3}$ Berbagai faktor juga telah dihubungkan dengan rendahnya pengetahuan ibu. Menurut Lawrence 
Green (1980) dalam praktik pemberian ASI eksklusif dapat dipengaruhi oleh beberapa hal, diantaranya tingkat pengetahuan ibu, pendidikan ibu, pekerjaan ibu, kondisi kesehatan ibu, umur ibu, sikap ibu, penolong persalinan, dan lingkungan keluarga. ${ }^{3}$

Banyak penelitian yang menyimpulkan bahwa ada hubungan pemberian ASI eksklusif dengan kejadian pneumonia. Menurut penelitian Juliastuti pada tahun 2011 menunjukan bahwa adanya hubungan antara tingkat pengetahuan ibu menyusui dengan penerapan ASI eksklusif, ibu yang memiliki tingkat pengetahuan baik berpeluang 7 kali lebih baik dalam penerapan ASI eksklusif dibandingkan ibu yang berpengetahuan cukup atau kurang, dan terdapat hubungan antara inisiasi menyusu dini dengan pemberian ASI eksklusif, dimana ibu yang melakukan inisiasi menyusu dini akan semakin tinggi pemberian ASI eksklusif. ${ }^{11}$

Berdasarkan uraian tersebut maka penulis bermaksud melakukan penelitian tentanghubungan faktor ibu dan inisiasi menyusui dini (IMD) dengan pemberian ASI eksklusif di Wilayah Kerja Puskesmas Sudiang Makassar.

\section{BAHAN DAN METODE}

Jenis penelitian yang digunakan adalah desain penelitian analitik cross sectional. Penelitian ini dilakukan di Wilayah Kerja Puskesmas Sudiang Makassar Provinsi Sulawesi Selatan. Penelitian ini dilakukan pada bulan September-Oktober 2019. Sampel penelitian ini adalah ibu yang memiliki anak berusia 6-11 bulan yang tinggal di Wilayah Puskesmas Sudiang Makassar.Sampel penelitian ini menggunakan Teknik pengambilan sampel dengan metode accidental sampling yaitu sebanyak 95 ibu.Analisis data dilakukan secara bertahap meliputi analisis univariat dan bivariat diuji secara statistik Chi square dengan derajat ketepatan 95\% $(\alpha=$ 0,05). Data penelitian diperoleh dengan mengumpulkan data primer dan data sekunder.Data primer yaitu anak berusia 6-11 bulan dengan pemberian ASI Eksklusif, dikumpulkan dengan menggunakan metode wawancara kepada ibu balita dengan bantuan kuesioner dan wawancara. Data sekunder diperoleh dari institusi atau pihak lain yang dapat dipercaya, yaitu presentasi pemberian ASI eksklusif di wilayah Puskesmas Sudiang sebesar 52,2 \%. Data dianalisis menggunakan SPSS untuk mengetahui distribusi frekuensi dari setiap variabel. Data yang telah dianalisis disajikan dalam bentuk tabel dan narasi untuk membahas hasil penelitian.

\section{HASIL}

Hasil penelitian distribusi karakteristik responden menunjukan bahwa dari 95 sampel diperoleh yaitu menurut umur responden, ibu yang memiliki umur 20 - 35 tahun lebih besar

yaitu 74 orang $(77,9 \%)$. Menurut tingkat pendidikan terakhir responden terbanyak terdapat pada tingkat pendidikan SMA/SMK yaitu 41 orang $(43,2 \%)$, dan menurut pekerjaan ibu paling banyak responden tidak bekerja atau hanya sebagai ibu rumah tangga (IRT) lebih besar yaitu 85 orang $(89,5 \%)$ 
Tabel 1.Distribusi Frequensi Karakteristik Responden di Wilayah KerjaPuskesmas Sudiang Makassar

\begin{tabular}{|c|c|c|}
\hline Karakteristik & $\mathbf{n}$ & $\%$ \\
\hline \multicolumn{3}{|l|}{ Umur (thn) } \\
\hline$<20$ & 7 & 7,4 \\
\hline $20-35$ & 74 & 77,9 \\
\hline$>35$ & 14 & 14,7 \\
\hline \multicolumn{3}{|l|}{ Pendidikan } \\
\hline Tidak Sekolah & 2 & 2,1 \\
\hline SD & 7 & 7,4 \\
\hline SMP & 27 & 28,4 \\
\hline SMA/SMK & 41 & 43,2 \\
\hline D3 & 3 & 3,2 \\
\hline S1 & 15 & 15,8 \\
\hline \multicolumn{3}{|l|}{ Pekerjaan } \\
\hline IRT & 85 & 89,5 \\
\hline Buruh & 3 & 3,2 \\
\hline Wiraswasta & 4 & 4,2 \\
\hline PNS & 3 & 3,2 \\
\hline \multicolumn{3}{|l|}{ Pengetahuan } \\
\hline Rendah & 27 & 28,4 \\
\hline Cukup & 51 & 53,7 \\
\hline Tinggi & 17 & 17,9 \\
\hline \multicolumn{3}{|l|}{ Sikap } \\
\hline Negatif & 53 & 55,8 \\
\hline Positif & 42 & 44,2 \\
\hline \multicolumn{3}{|l|}{ Psikologis } \\
\hline Tidak Baik & 25 & 26,3 \\
\hline Baik & 70 & 73,7 \\
\hline \multicolumn{3}{|l|}{ IMD } \\
\hline Tidak IMD & 16 & 16,8 \\
\hline IMD & 79 & 83,2 \\
\hline \multicolumn{3}{|l|}{ ASI Eksklusif } \\
\hline Tidak ASI & 48 & 50,5 \\
\hline ASI & 47 & 49,5 \\
\hline
\end{tabular}

Sumber : Data Primer, 2019.

Hasil univariat menunjukan pengetahuan ibu paling banyak responden yang memiliki pengetahuan cukup sebanyak 51 orang $(53,7 \%)$, responden dengan pengetahuan rendah sebanyak 27 orang $(28,4 \%)$, dan responden dengan pengetahuan tinggi sebanyak 17 orang $(17,9 \%)$. Menurut sikap ibu paling banyak responden yang memiliki sikap negatif sebanyak 53 orang $(55,8 \%)$ dan responden dengan sikap positif sebanyak 42 orang $(44,2 \%)$. Menurut psikologis ibu paling banyak responden yang memiliki psikologis baik sebanyak 70 orang $(73,7 \%)$ dan responden dengan psikologis tidak baik sebanyak 25 orang (26,3\%). Menurut inisiasi menyusu dini (IMD) paling banyak responden yang memberikan inisiasi menyusu dini sebanyak 79 orang 
$(83,2 \%)$ dan responden yang tidak memberikan inisiasi menyusu dini sebanyak 16 orang (16,8\%). Menurut pemberian ASI eksklusif paling banyak responden yang tidak memberikan ASI eksklusif sebanyak 48 orang $(50,5 \%)$ dan responden yang memberikan ASI eksklusif sebanyak 47 orang $(49,5 \%)$.

Tabel 2. Distribusi Frekuensi Responden Berdasarkan Pengetahuan Ibu

\begin{tabular}{ccccccccc}
\hline Pemberian & \multicolumn{4}{c}{ Pengetahuan Ibu } & \multicolumn{3}{c}{ Total } \\
\cline { 2 - 10 } ASI Eksklusif & $\begin{array}{c}\text { Rendah } \\
(\mathbf{n})\end{array}$ & \% & $\begin{array}{c}\text { Cukup } \\
(\mathbf{n})\end{array}$ & $\mathbf{\%}$ & $\begin{array}{c}\text { Tinggi } \\
(\mathbf{n})\end{array}$ & $\mathbf{\%}$ & $\mathbf{N}$ & $\%$ \\
\hline $\begin{array}{c}\text { Tidak ASI } \\
\text { Ekslusif }\end{array}$ & 20 & 41,7 & 21 & 43,8 & 7 & 14,6 & 48 & 100 \\
\hline ASI Eksklusif & 7 & 14,9 & 30 & 63,8 & 10 & 21,3 & 47 & 100 \\
\hline
\end{tabular}

Sumber : Data Primer, 2019.

Tabel 3. Distribusi Frekuensi Responden Berdasarkan Sikap Ibu

\begin{tabular}{ccccccc}
\hline $\begin{array}{c}\text { Pemberian ASI } \\
\text { Eksklusif }\end{array}$ & \multicolumn{3}{c}{ Sikap Ibu } & \multicolumn{2}{c}{ Total } \\
\cline { 2 - 8 } & $\begin{array}{c}\text { Negatif } \\
(\mathbf{n})\end{array}$ & $\%$ & $\begin{array}{c}\text { Positif } \\
(\mathbf{n})\end{array}$ & $\mathbf{\%}$ & $\mathbf{N}$ & $\boldsymbol{\%}$ \\
\hline $\begin{array}{c}\text { Tidak ASI } \\
\text { Ekslusif }\end{array}$ & 26 & 54,2 & 22 & 45,8 & 48 & 100 \\
\hline ASI Eksklusif & 27 & 57,4 & 20 & 42,6 & 47 & 100 \\
\hline
\end{tabular}

Sumber : Data Primer, 2019.

Tabel 4. Distribusi Frekuensi Responden Berdasarkan Umur Ibu

\begin{tabular}{|c|c|c|c|c|c|c|}
\hline \multirow[t]{2}{*}{$\begin{array}{c}\text { Pemberian ASI } \\
\text { Eksklusif }\end{array}$} & \multicolumn{4}{|c|}{$\begin{array}{c}\text { Umur Ibu } \\
\text { (thn) }\end{array}$} & \multicolumn{2}{|c|}{ Total } \\
\hline & $\underset{\text { (n) }}{<20 \text { dan }}>35$ & $\%$ & $\begin{array}{c}20-35 \\
\text { (n) }\end{array}$ & $\%$ & $\mathbf{N}$ & $\%$ \\
\hline $\begin{array}{l}\text { Tidak ASI } \\
\text { Ekslusif }\end{array}$ & 11 & 22,9 & 37 & 77,1 & 48 & 100 \\
\hline ASI Eksklusif & 15 & 31,9 & 32 & 68,11 & 47 & 100 \\
\hline
\end{tabular}

Sumber : Data Primer, 2019.

Tabel 5. Distribusi Frekuensi Responden Berdasarkan Pendidikan Ibu

\begin{tabular}{ccccccc} 
Pemberian ASI & \multicolumn{3}{c}{ Pendidikan Ibu } & \multicolumn{2}{c}{ Total } \\
\cline { 2 - 7 } Eksklusif & $\begin{array}{c}\text { Rendah } \\
(\mathbf{n})\end{array}$ & $\mathbf{\%}$ & $\begin{array}{c}\text { Tinggi } \\
(\mathbf{n})\end{array}$ & $\mathbf{\%}$ & $\mathbf{N}$ & $\mathbf{\%}$ \\
\hline $\begin{array}{c}\text { Tidak ASI } \\
\text { Ekslusif }\end{array}$ & 17 & 35,4 & 31 & 64,6 & 48 & 100 \\
\hline ASI Eksklusif & 14 & 29,8 & 33 & 70,2 & 47 & 100 \\
\hline
\end{tabular}

Sumber : Data Primer, 2019. 
Tabel 6. Distribusi Frekuensi Responden Berdasarkan Pekerjaan Ibu

\begin{tabular}{ccccccc}
\hline $\begin{array}{c}\text { Pemberian ASI } \\
\text { Eksklusif }\end{array}$ & $\begin{array}{c}\text { Tidak } \\
\text { Bekerja } \\
(\mathbf{n})\end{array}$ & $\mathbf{\%}$ & $\begin{array}{c}\text { Bekerja } \\
(\mathbf{n})\end{array}$ & $\mathbf{\%}$ & $\mathbf{N}$ & $\mathbf{\%}$ \\
\cline { 2 - 7 } & 40 & 83,3 & 8 & 16,7 & 48 & 100 \\
\hline $\begin{array}{c}\text { Tidak ASI } \\
\text { Ekslusif }\end{array}$ & 45 & 95,7 & 2 & 4,3 & 47 & 100 \\
\hline ASI Eksklusif & & & & & \\
\hline
\end{tabular}

Sumber : Data Primer, 2019.

Tabel 7. Distribusi Frekuensi Responden Berdasarkan Psikologi Ibu

\begin{tabular}{ccccccc}
\hline $\begin{array}{c}\text { Pemberian ASI } \\
\text { Eksklusif }\end{array}$ & \multicolumn{3}{c}{ Psikologis Ibu } & \multicolumn{2}{c}{ Total } \\
\cline { 2 - 7 } & $\begin{array}{c}\text { Tidak baik } \\
(\mathbf{n})\end{array}$ & $\mathbf{\%}$ & $\begin{array}{c}\text { Baik } \\
(\mathbf{n})\end{array}$ & $\mathbf{\%}$ & $\mathbf{N}$ & $\mathbf{\%}$ \\
\hline $\begin{array}{c}\text { Tidak ASI } \\
\text { Ekslusif }\end{array}$ & 8 & 16,7 & 40 & 83,3 & 48 & 100 \\
\hline ASI Eksklusif & 17 & 36,2 & 30 & 63,8 & 47 & 100 \\
\hline
\end{tabular}

Sumber : Data Primer, 2019.

Tabel 8. Distribusi Frekuensi Responden Berdasarkan Inisiasi Menyusui Dini Ibu

\begin{tabular}{ccccccc}
\hline $\begin{array}{c}\text { Pemberian ASI } \\
\text { Eksklusif }\end{array}$ & \multicolumn{3}{c}{ Inisiasi Menyusu Dini (IMD) } & \multicolumn{2}{c}{ Total } \\
\cline { 2 - 8 } & $\begin{array}{c}\text { Tidak } \\
\text { Melakukan IMD } \\
(\mathbf{n})\end{array}$ & $\mathbf{\%}$ & $\begin{array}{c}\text { Melakukan IMD } \\
(\mathbf{n})\end{array}$ & $\mathbf{\%}$ & $\mathbf{n}$ & $\mathbf{\%}$ \\
\hline $\begin{array}{c}\text { Tidak ASI } \\
\text { Ekslusif }\end{array}$ & 13 & 27,1 & 35 & 72,9 & 48 & 100 \\
\hline ASI Eksklusif & 3 & 6,4 & 44 & 93,6 & 47 & 100 \\
\hline
\end{tabular}

Sumber : Data Primer, 2019.

\section{PEMBAHASAN}

Hasil penelitian menunjukan bahwa dari 95 orang ibu yang diteliti, hanya 47 orang ibu (49,5\%) ibu yang memberikan ASI eksklusif. Sedangkan yang lain tidak memberikan ASI eksklusif. Penelitian ini mencerminkan bahwa pemberian ASI eksklusif di wilayah Kerja Puskesmas Sudiang Makassar masih rendah, jika dibandingkan dengan target yang menjadi indicator Indonesia Sehat 2010 bahwa cakupan pemberian ASI eksklusif adalah 80\%.

Berdasarkan hasil analisi menggunakan uji chi_square diperoleh $\mathrm{p}=0,015 \quad(\mathrm{p}<0,05)$ sehingga dapat disimpulkan bahwa ada hubungan pengetahuan ibu dengan pemberian ASI eksklusif di Wilayah Kerja Puskesmas Sudiang Makassar. Hasil penelitian ini sejalan dengan penelitian Septiani (2017) terdapat hubungan yang signifikan antara pengetahuan ibu dengan 
pemberian ASI eksklusif $(\mathrm{p}=0,000)$. Pemberian ASI eksklusif dapat terjadi jika ibu memiliki pengetahuan yang tinggi.

Menurut teori Green bahwa perilaku dipengaruhi oleh 3 faktor utama dimana salah satu factor predisposisi yang ada di dalamnya terdapat pengetahuan. ${ }^{4}$ Hasil ini sejalan dengan teori yang menyatakan bahwa pengetahuan atau kognitif merupakan domain yang sangat penting dalam membentuk tindakan seseorang. ${ }^{4}$ Dari pengalaman dan penelitian terbukti bahwa perilaku yang didasari oleh pengetahuan lebih langgeng daripada perilaku yang tidak didasari pengetahun. ${ }^{4}$

Pengetahuan merupakan domain yang cukup penting dalam menentukan perilaku. Perilaku yang didasari pengetahuan, kesadaran dan sikap positif akan semakin langgeng. Pengetahuan yang baik akan memudahkan seseorang untuk merubah perilaku termasuk dalam praktik menyusui. Perilaku ibu untuk memberikan ASI eksklusif disebabkan oleh factor penyebab perilaku yang salah satunya adalag pengetahuan, dimana factor ini menjadi dasar atau motivasi bagi individu dalam mengambil keputusan. ${ }^{5}$

Hasil analisis diperoleh $p=0,748(\mathrm{p}>0,05)$ yang berarti tidak terdapat hubungan antara sikap ibu dengan pemberian ASI eksklusif. Hal ini sejalan dengan penelitian yang dilakukan oleh Ida (2012) tidak terdapat hubungan yang signifikan antara sikap ibu dengan pemberian ASI eksklusif nilai $p=0,154$.Sikap (attitude) merupakan konsep paling penting dalam psikologi sosial yang membahas unsur sikap baik sebagai individu maupun kelompok. Sikap dan kepercayaan yang tidak mendasar terhadap makna pemberian ASI yang membuat para ibu tidak melakukan ASI eksklusif selama 6 bulan. Umumnya alasan ibu tidak memberikan ASI eksklusif meliputi rasa takut yang tidak mendasar bahwa ASI yang dihasilkan tidak cukup atau memiliki mutu yang tidak baik, keterlambatan memulai pemberian ASI, pembuangan kolostrum, teknik pemberian ASI yang salah, serta kepercayaan yang keliru bahwa bayi haus dan memerlukan cairan tambahan lainnya. ${ }^{6}$

Hasil analisis diperoleh $p=0,325(\mathrm{p}>0,05)$ yang berarti tidak terdapat hubungan antara umur ibu dengan pemberian ASI eksklusif. Hal ini sejalan dengan penelitian yang dilakukan oleh Sugianto (2016) tidak terdapat hubungan yang signifikan antara sikap ibu dengan pemberian ASI eksklusif nilai $p=0,927$.Umur ibu sangat menentukan kesehatan maternal karena berkaitan dengan kondisi kehamilan, persalinan dan nifas, serta cara mengasuh juga menyusui bayinya. Ibu yang berumur kurang dari 20 tahun masih belum matang dan belum siap secara jasmani dan sosial dalam menghadapi kehamilan, persalinan, dan menyusui bayi yang dilahirkan. Sedangkan pada usia 35 tahun ke atas di mana produksi hormon relatif berkurang, mengakibatkan proses laktasi menurun, sedangkan pada usia remaja 20 tahun kebawah perkembangan fisik, psikologis, maupun sosial belum siap sehingga dapat mengganggu keseimbangan psikologis dan dapat mempengaruhi dalam produksi ASI. ${ }^{4}$

Usia 20-35 tahun adalah usia reproduksi sehat dan matang sehingga dapat sangat mendukung untuk pemberian ASI eksklusif, sedangkan usia 35 tahun meskipun memiliki bayi dengan status gizi baik namun pada usia tersebut dianggap berbahaya, sebab baik alat reproduksinya maupun fisik ibu sudah jauh berkurang dan menurun, selain itu bisa terjadi resiko 
bawaan pada bayinya dan juga dapat meningkatkan kesulitan pada kehamilan, persalinan, dan nifas. $^{4}$

Hasil analisis diperoleh $p=0,558(\mathrm{p}>0,05)$ yang berarti tidak terdapat hubungan antara pendidikan ibu dengan pemberian ASI eksklusif. Hal ini sejalan dengan penelitian yang dilakukan oleh Santono (2012) tidak terdapat hubungan yang signifikan antara pendidikan ibu dengan pemberian ASI eksklusif.Tingkat Pendidikan ibu yang semakin rendah berpengaruh pada kurangnya kemampuan dasar berpikir untuk mengambil keputusan, khususnya pemberian ASI eksklusif. Pemberian ASI eksklusif tidak hanyak dipengaruhi oleh factor Pendidikan ibu, tetapi juga tingkat pengetahuan yang ibu miliki mengenai ASI eksklusif. Pengetahuan bisa di dapatkan melalui penyuluhan kesehatan, brosur dan pemberian informasi petugas kesehatan saat datang ke posyandu. $^{7}$

Hasil analisis diperoleh $p=0,049(\mathrm{p}<0,05)$ yang berarti terdapat hubungan antara pekerjaan ibu dengan pemberian ASI eksklusif. Hal ini sejalan dengan penelitian yang dilakukan oleh Bahriyah (2017) terdapat hubungan yang signifikan antara pekerjaan ibu dengan pemberian ASI eksklusif.Kecenderungan ibu-ibu tidak memberikan ASI eksklusif dikarenakan banyaknya ibu-ibu yang bekerja. Selain itu, kecenderungan ini juga terjadi dikarenakan bagi pekerja wanita yang melahirkan, memberikan ASI eksklusif merupakan suatu dilemma, karena masa cuti terlalu singkat dibandingkan masa menyusui, sehingga mereka akan memberikan susu formula sebagai pengganti ASI eksklusif. ${ }^{8}$ Ibu yang bekerja diluar rumah mempunyai keterbatasan kesempatan untuk menyusui bayinya secara langsung. Keterbatasan ini bisa berupa waktu dan tempat, terutama jika ditemapt kerja tidak tersedia fasilitas. Jika ibu bekerja mempunyai pengetahuan yang cukup mengenai manfaat, cara penyimpanan, termasuk juga pemberian ASI diharapkan dapat meningkatkan cakupan pemberian ASI eksklusif. ${ }^{8}$

Hasil analisis diperoleh $p=0,031 \quad(\mathrm{p}<0,05)$ yang berarti terdapat hubungan antara psikologis ibu dengan pemberian ASI eksklusif. Hal ini sejalan dengan penelitian yang dilakukan oleh Sinta (2015) terdapat hubungan yang signifikan antara pekerjaan ibu dengan pemberian ASI eksklusif nilai $\mathrm{p}=0,012$.Hal ini dikarenakan apabila psikologis ibu baik, ibu akan memberikan ASI pada bayi selama 6 bulan. Menurut Roesli (2007) yang menegaskan bahwa ibu yang tenang, bahagai, percaya diri dan tidak sedang mengalami stress akan memperlancar produksi ASI karena kondisi ibu turut mempengaruhi cara kerja hormone oksitosin yang dibutuhkan untuk memproduksi ASI.Timbulnya stress pada ibu yang menyusui berasal dari berbagai sumber diantaranya adalah karena beberapa perubahan baru yang dialami ibu baik berupa perubahan secara biologis, fisioklogis, dan perubahan peran serta tanggung jawab baru yang dimiliki. ${ }^{9}$

Hasil analisis diperoleh $\mathrm{p}=0,007(\mathrm{p}<0,05)$ yang berarti terdapat hubungan antara inisiasi menyusu dini (IMD) dengan pemberian ASI eksklusif. Hal ini sejalan dengan penelitian yang dilakukan oleh Sofia (2018) terdapat hubungan yang signifikan antara inisiasi menyusu dini (IMD) dengan pemberian ASI eksklusif nilai $\mathrm{p}=0,001$. Inisiasi menyusu dini (IMD) akan mempengaruhi seorang ibu untuk memberikan ASI selanjutnya termasuk ASI eksklusif samapi dengan 6 bulan sert ASI dengan makanan tambahan sampai dengan 2 tahun. Disamping itu, konsumsi makanan iby yang cukuo juga mempengaruhi pemberian ASI eksklusif. Menurut teori 
Curningham G (2005)seorang ibu yang menyusui dapat dengan mudah memproduksi $600 \mathrm{ml}$ ASI per hari. Semua vitamin kecuali Vitamin K terkandung dalam ASI tetapi dalam jumlah yang bervariasi dan pemberian makanan tambahan pada ibu akan meningkatkan sekresinya. ${ }^{10}$

\section{KESIMPULAN}

Dapat disimpulankan bahwa tidak terdapat hubungan antara sikap ibu, umur ibu, dan pendidikan ibu dengan pemberian ASI eksklusif, Sedangkan terdapat hubungan antara pengetahuan ibu, pekerjan ibu, psikologis ibu dan terdapat hubungan antara inisiasi menyusu dini (IMD) dengan pemberian ASI eksklusif. Hal ini dapat dilihat bahwa beberapa faktor internal dan ekskteral dapat mempengaruhi pemberian ASI eksklusif. Saran lebih meningkatkan promosi ASI eksklusif dan tidak memperkenalkan atau menganjurkan pada ibu menyusui untuk memberikan susu formula sebagai pengganti ASI eksklusif, lebih mensosialisasikan ASI eksklusif pada ibu bekerja maupun tidak bekerja, untuk meningkatkan pengetahuan tentang pemberian ASI eksklusif dengan mengikuti penyuluhan dan mencari informasi melalui media cetak atau elektronik

\section{DAFTAR PUSTAKA}

1. Departemen Kesehatan RI. Bangsa Sehat Berprestasi Melalui Percepatan Perbaikan Gizi Pada 1000 Hari Pertama Kehidupan. Artik Kementrian Republik Indones. 2016.

2. Kesehatan K. Hasil Utama Riskesdas 2018. 2018.

3. Fikawati, S. And Syafiq A. Penyebab Keberhasilan Dan Kegagalan Praktik Pemberian ASI Eksklusif. 2009.

4. Atabik A. Faktor Ibu Yang Berhubungan Dengan Praktik Pemberian ASI Eksklusif Di Wilayah Kerja Puskesmas Pamotan. 2013.

5. Associated F, Exclusive W, By B, Who W, Personnel Asah. Faktor-Faktor Yang Berhubungan Dengan Pemberian ASI Eksklusif Oleh Ibu Menyusui Yang Bekerja Sebagai Tenaga Kesehatan. 2017;2(2):159-74.

6. Wawan, A. \& D. Teori Dan Pengukuran Pengetahuan Sikap Dan Perilaku Manusia. Yogyakarta: Penerbit Nuha Medika. 2010.

7. Hastuti1 Bw, Machfudz2 S, Febriani2 Tb. Hubungan Pengalaman Menyusui Dan Tingkat Pendidikan Ibu Dengan Pemberian ASI Eksklusif Di Kelurahan Barukan, Kecamatan Manisrenggo, Kabupaten Klaten. 2015;6(4):179-87.

8. Bahriyah F, Putri M, Jaelani AK, Indragiri AK. Hubungan Pekerjaan Ibu Terhadap Pemberian ASIEsklusif Pada Bayi. 2017;2(June):113-8.

9. Utami R. Inisiasi Menyusu Dini plus ASI Eksklusif. Jakarta: Pustaka Bunda. 2012.

10. Annisa Septy Nurcahyani. Hubungan Inisiasi Menyusu Dini Dengan Keberhasilan ASIEksklusif di Wilayah Kerja Puskesmas godean ii. 2017;1-12.

11. Juliastuti, R. (2011) 'Hubungan Tingkat Pengetahuan, Status Pekerjaan Ibu, Dan Pelaksanaan Inisiasi Menyusu Dini Dengan Pemberian Asi Eksklusif’, Journal, pp. 1-87. 